\title{
Disclosing pathogenic genetic variants to research participants: Quantifying an emerging ethical responsibility
}

\author{
Christopher A. Cassa, ${ }^{1,2,3,9}$ Sarah K. Savage, ${ }^{3}$ Patrick L. Taylor, ${ }^{4}$ Robert C. Green, ${ }^{2,5,6}$ \\ Amy L. McGuire, ${ }^{7}$ and Kenneth D. Mandl ${ }^{1,2,3,8}$ \\ ${ }^{1}$ Children's Hospital Informatics Program, Children's Hospital Boston, Boston, Massachusetts 02115, USA; ${ }^{2}$ Harvard Medical School, \\ Harvard University, Boston, Massachusetts 02115, USA; ${ }^{3}$ Children's Hospital Boston, Boston, Massachusetts 02115, USA; ${ }^{4}$ Petrie-Flom \\ Center of Harvard Law School, Cambridge, Massachusetts 02138, USA; ${ }^{5}$ Division of Genetics, Brigham and Women's Hospital, \\ Harvard Medical School, Boston, Massachusetts 02115, USA; ${ }^{6}$ Partners Healthcare Center for Personalized Genetic Medicine, Harvard \\ Medical School, Boston, Massachusetts 02115, USA; ${ }^{7}$ Center for Medical Ethics and Health Policy, Baylor College of Medicine, Houston, \\ Texas 77030, USA; ${ }^{8}$ Center for Biomedical Informatics, Harvard Medical School, Boston, Massachusetts 02115, USA
}

\begin{abstract}
There is an emerging consensus that when investigators obtain genomic data from research participants, they may incur an ethical responsibility to inform at-risk individuals about clinically significant variants discovered during the course of their research. With whole-exome sequencing becoming commonplace and the falling costs of full-genome sequencing, there will be an increasingly large number of variants identified in research participants that may be of sufficient clinical relevance to share. An explicit approach to triaging and communicating these results has yet to be developed, and even the magnitude of the task is uncertain. To develop an estimate of the number of variants that might qualify for disclosure, we apply recently published recommendations for the return of results to a defined and representative set of variants and then extrapolate these estimates to genome scale. We find that the total number of variants meeting the threshold for recommended disclosure ranges from 3955-12,579 (3.79\%-12.06\%, 95\% Cl) in the most conservative estimate to $6998-17,189(6.69 \%-16.48 \%$, $95 \% \mathrm{Cl}$ ) in an estimate including variants with variable disease expressivity. Additionally, if the growth rate from the previous $4 \mathrm{yr}$ continues, we estimate that the total number of disease-associated variants will grow $37 \%$ over the next 4 yr.
\end{abstract}

[Supplemental material is available for this article.]

In genomics, there is an emerging consensus that when investigators obtain genetic data from research participants, they may incur an ethical responsibility to inform at-risk individuals about clinically significant variations discovered during the course of their research (Bookman et al. 2006; Wolf et al. 2008a,b; Fabsitz et al. 2010). Perhaps the largest obstacle to reviewing and communicating incidental findings in genomics research is the sheer magnitude of the task. When performing whole-genome sequencing, we expect to observe hundreds of variants in each individual participant from the over 100,000 variants that have been previously associated with disease (Ashley et al. 2010). The proportion of these that would meet criteria for disclosure has not previously been considered.

Because of the complexities inherent in exposing participants to predictive genetic information discovered outside of the clinical context (Kohane et al. 2006; Meltzer 2006; Wolf et al. 2008a; Johnson et al. 2010) and because of concerns about blurring the lines between research and clinical care (Caulfield et al. 2008), there has been extensive debate about whether it is appropriate to communicate results derived from genetic research to study participants (Fernandez et al. 2003; Bookman et al. 2006; Fernandez and Weijer 2006; MacNeil and Fernandez 2006; Meltzer 2006;

\footnotetext{
${ }^{9}$ Corresponding author.

E-mail cassa@alum.mit.edu.

Article published online before print. Article, supplemental material, and publication date are at http://www.genome.org/cgi/doi/10.1101/gr.127845.111. Freely available online through the Genome Research Open Access option.
}

Kozanczyn et al. 2007; Wolf et al. 2008a,b; Fabsitz et al. 2010). Several bodies have presented recommendations for the return of individual genetic results to participants, including the National Bioethics Advisory Commission (NBAC), the Centers for Disease Control and Prevention (CDC), the National Cancer Institute (NCI), and the National Heart, Lung, and Blood Institute (NHLBI) (Table 1; Beskow et al. 2001; White and Gamm 2002; Bookman et al. 2006; Teutsch et al. 2009; Fabsitz et al. 2010; http://biospecimens.cancer.gov/ resources/publications/workshop/rrra.asp). Although these recommendations vary, they all recognize an obligation to return at least some research findings. While there is no set of universally accepted standards for disclosure, there is some similarity among their criteria for returning individual research results to participants. Each of these groups places priority on the scientific validity of the reported association, the clinical significance of the associated phenotype, and the availability of beneficial medical interventions.

In support of translational medicine, hundreds of thousands of participants have provided samples to research biorepositories (Kohane et al. 2007; McGuire 2008; Roden et al. 2008; Blow 2009). Inevitably, analyses of these samples will identify both novel and previously discovered variants that confer disease risk. Considering that there are already over 100,000 genetic variants cited in the medical literature (Hindorff et al. 2011), how many of these variants will meet an ethical obligation for disclosure to participants?

To answer this question, we estimated the proportion of known genomic variants that would meet the expectation to report to participants based on published guidelines, using the most recently published recommendations (Fabsitz et al. 2010) as a model. These 
Table 1. Summary of key U.S. guidelines on the return of genetic research results

\begin{tabular}{|c|c|c|}
\hline & Disclosure policy & $\begin{array}{l}\text { To whom information } \\
\text { can be disclosed }\end{array}$ \\
\hline $\begin{array}{l}\text { National Bioethics Advisory } \\
\text { Commission, } 1999\end{array}$ & $\begin{array}{l}\text { Individual data only if valid, confirmed, } \\
\text { have significant health implications, } \\
\text { can treat or ameliorate }\end{array}$ & Research participant \\
\hline $\begin{array}{l}\text { Centers for Disease Control } \\
\text { and Prevention, } 2001\end{array}$ & $\begin{array}{l}\text { Aggregate and individual data only if } \\
\text { likely to lead to evidence-based } \\
\text { intervention }\end{array}$ & Research participant \\
\hline RAND Corp., 2003 & Aggregate data only & $\begin{array}{l}\text { Public: via internet, newsletter, } \\
\text { scientific meeting }\end{array}$ \\
\hline $\begin{array}{l}\text { National Heart, Lung, and } \\
\text { Blood Institute (NHLBI), } 2004\end{array}$ & $\begin{array}{l}\text { Individual data only if analytically valid, } \\
\text { replicable, and significant; have severe } \\
\text { health implications; can treat or prevent }\end{array}$ & Research participant \\
\hline National Cancer Institute (NCl), 2007 & Aggregate and individual data & $\begin{array}{l}\text { Research participant, participant's } \\
\text { health care provider, family }\end{array}$ \\
\hline $\begin{array}{l}\text { Public Responsibility in Medicine } \\
\text { and Research, } 2007\end{array}$ & Individual data only if compelling rationale & Research participant $^{\mathrm{a}}$ \\
\hline $\begin{array}{l}\text { National Institutes of Health } \\
\text { Genome-Wide Association } \\
\text { Studies, } 2007\end{array}$ & Individual data only in rare circumstances & $\begin{array}{l}\text { Downstream users disclose to } \\
\text { contributing investigator }\end{array}$ \\
\hline $\begin{array}{l}\text { National Human Genome Research } \\
\text { Institute, } 2008\end{array}$ & $\begin{array}{l}\text { Right to access individual data unless results } \\
\text { are of unproven clinical validity and } \\
\text { judged by IRB to be of no benefit to subjects }\end{array}$ & Research participant \\
\hline NHLBI, 2010 & $\begin{array}{l}\text { Individual data only if analytically valid, } \\
\text { replicable, and significant, have important } \\
\text { health implications, can treat or prevent }\end{array}$ & Research participant \\
\hline $\mathrm{NCl}, 2011$ & $\begin{array}{l}\text { Aggregate and individual data if research } \\
\text { participant has consented to receive research } \\
\text { results and if results are analytically valid, } \\
\text { clinically significant or serious, and clinically } \\
\text { actionable }\end{array}$ & Research participant \\
\hline
\end{tabular}

While there is no universally accepted set of standards for the return of genetic research results, many of the groups that have visited this issue have placed priority on the scientific validity, clinical significance, and availability of medical interventions. This is a representative list of U.S. guidelines. It is not intended to be exhaustive.

${ }^{a}$ Research participant must be informed about plans to disclose so investigator can disclose to others with participant consent.

recommendations were selected because they incorporate most of the commonly articulated criteria. The NHLBI 2010 working group concluded that individual genetic results should (with conditions) be offered to study participants in a timely manner if they meet all of the following criteria (recommendation 1):

1. The genetic finding has important health implications for the participant and the associated risks are established and substantial.

2. The genetic finding is actionable; that is, there are established therapeutic or preventive interventions or other available actions that have the potential to change the clinical course of the disease.

3. The test is analytically valid and complies with all applicable laws.

4. During the informed consent process or subsequently, the study participant has opted to receive his/her individual genetic results.

We selected a representative sample of disease-associated genetic variants from the scientific literature and reviewed each variant to assess the characteristics that would help determine whether investigators would be expected to report it according to these 2010 recommendations. We then extrapolated these results to the genome scale, estimating the total number of variants that would satisfy these disclosure criteria.

\section{Results}

An expert committee of three certified genetic counselors reviewed and scored a representative sample of 160 disease-associated variants that were randomly sampled from databases that curate genetic findings from the scientific literature. Each variant was scored on multiple characteristics, including the validity of its disease association, the severity of the associated disease with and without treatment, and the potential to improve medical outcome with intervention. We then applied disclosure criteria from the 2010 guidelines (Fabsitz et al. 2010) to the sample under the strictest possible interpretation and then again with an interpretation that allowed for greater variability of disease expression. Finally, we extrapolated these results to the genome scale, estimating the total number of variants that would satisfy these disclosure criteria (Table 2).

Under the strictest interpretation, which required possible expression of severe disease, we identified that $6.9 \%$ of the variants reviewed would meet criteria for disclosure to research participants. An additional $3.8 \%$ of all sampled variants is associated with variable disease expression or uncertain risk for severe disease and would meet the criteria for disclosure if disease expression were at

\section{Genome Research


Table 2. Applying return of results recommendations to our set of genetic variant annotations

National Heart, Lung, and Blood Institute (NHLBI) 2010 recommendation 1 as applied to our variant annotations

\begin{tabular}{|c|c|c|c|c|c|c|}
\hline \multirow{3}{*}{$\begin{array}{l}\text { Constraint } \\
\text { All must be met }\end{array}$} & \multirow{2}{*}{$\begin{array}{c}\text { Criterion } \\
\text { Validity of association }\end{array}$} & \multicolumn{5}{|c|}{ Value (ranges from low to high, left to right) } \\
\hline & & \multicolumn{2}{|r|}{ Low } & Moderate & \multicolumn{2}{|c|}{ High } \\
\hline & \multirow{3}{*}{$\begin{array}{l}\text { Phenotypic severity } \\
\text { Improves with treatment } \\
\text { Analytic validity and laws } \\
\text { Participant consent }\end{array}$} & 1 & 2 & 3 & 4 & 5 \\
\hline & & 0 & 1 & 2 & 3 & 4 \\
\hline & & \multicolumn{5}{|c|}{$\begin{array}{l}\text { We assume legal testing in a Clinical Laboratory Improvement Amendment-approved laboratory } \\
\text { We assume that the participant has consented }\end{array}$} \\
\hline
\end{tabular}

Each variant in this study was reviewed and annotated by an expert committee of three genetic counselors and was given a score for each of the criteria cited in the National Heart, Lung, and Blood Institute (NHLBI) 2010 recommendations. If each of the values for the variant met the recommendations (in the zone highlighted in gray in each row), then that variant was judged to have met all criteria to warrant disclosure. If the score for even one criterion is in a zone in white, there is no responsibility to disclose the variant to a participant.

least "severe" in some cases. With these additional variants included, $10.6 \%$ meets the criteria for disclosure.

Among the 104,304 disease-associated variants genome-wide from the published research considered in our study (a sample of 160 randomly sampled from curated pathogenic variant databases: Human Gene Mutation Database (HGMD), Online Mendelian Inheritance in Man (OMIM), and National Human Genome Research Institute (NHGRI) Catalog of Genome-Wide Association Studies (GWAS) (Amberger et al. 2009; Stenson et al. 2009; Hindorff et al. 2011), we conservatively estimate that investigators could be urged to share 7171 [3955-12,579, 95\%CI] of those variants with participants. If variants with variable disease expression are included (which meet all other required criteria and also may result in severe disease,) then 11,082 [6998-17,189, 95\%CI] variants would be shared, genome-wide (Table 3 ).

We further project an increase in the number of diseaseassociated variants that will be identified in publications. By using $4 \mathrm{yr}$ of historical disease-associated variant data from HGMD and the NHGRI Catalog of Published GWAS (98\% of our variant data set) at a quarter-year resolution, we identified an average growth rate of 10,437 variants per annum $\left(R^{2}=0.9977\right)$ in a conservative linear growth scenario and increasing growth rates in more aggressive scenarios (Fig. 1).

It is expected that by 2015 , there will be over 150,000 published disease-associated variants using a conservative linear estimate and over 190,000 if extrapolating using an exponential growth model. Estimates are presented for growth in the number of variants that would meet the recommendation to share with participants if a conservative, steady growth (linear model, $\mathrm{R}^{2}=0.9976$ ) is selected (Table 4 ), when extrapolating the observed $10.6 \%$ variant disclosure rate from our sample using Fabsitz et al. (2010) recommendation 1.

Additionally, to evaluate the number of variants we might encounter in research subjects, we analyzed 36 whole-genome sequences of asymptomatic individuals that were publicly available from Complete Genomics (Drmanac et al. 2010; http://www. completegenomics.com/sequence-data/download-data/). We iden- tified that each of these samples carried an average of 2120 substitution variants from our study knowledge base (Table 5). This demonstrates that a substantial number of previously identified variants are likely to be observed in the whole-genome sequence analysis of asymptomatic individuals, although it is not yet possible to accurately estimate the actual number of these variants that will be reportable to each individual.

\section{Discussion}

This is the first study to estimate the number of published diseaseassociated variants that met the criteria for disclosure to research participants, according to the recommendations of a recent consensus group (Fabsitz et al. 2010). Extrapolating to genome scale, investigators following these guidelines may be responsible for disclosing over 11,000 variants today and over 16,000 variants by the year 2015 .

The return of incidental research findings has been the subject of debate for many years. Still contentious and unresolved, for example, is the optimal approach to disclosing suspicious incidental findings to subjects of neuroimaging studies (Illes et al. 2004, 2010; Palmour et al. 2011). Finding a lesion on the computed tomography scan of an asymptomatic research subject creates a complex dilemma; the meaning of the lesion may be unclear when the prior probability of disease is low (Sadatsafavi et al. 2010; http:// bioethics.gov/cms/meeting-four-agenda). In genomics, the core ethical issues are similar, but the information management task becomes daunting at the genome scale.

Without new tools for investigators and institutions, emerging requirements for the return of results in genomics may become rapidly unmanageable in the setting of a growing corpus of known disease-associated variants. The scientific review process to measure the validity and communicability criteria for each of these variants would be protracted, and even once the estimated 11,00016,000 qualified variants are identified, there is the process of evaluating and prioritizing those identified in each participant.

Table 3. The number of variants from our sample that would be shared with participants according to National Heart, Lung, and Blood Institute (NHLBI) 2010

\begin{tabular}{lcccc}
\hline Variant sample & $\begin{array}{c}\text { Ethical obligation to } \\
\text { disclose the variant }\end{array}$ & $\begin{array}{c}\text { Variant may be disclosed } \\
\text { (variable disease expression) }\end{array}$ & $\begin{array}{c}\text { No ethical obligation } \\
\text { to disclose variant }\end{array}$ & $\begin{array}{c}\text { Unknown or } \\
\text { insufficient information }\end{array}$ \\
\hline NHLBI 2010 sample & $11(6.88 \%)[3.80-12.06]$ & $6(3.75 \%)[1.58-8.17]$ & $140(87.50 \%)[81.37-91.80]$ & $3(1.88 \%)[0.42-5.68]$ \\
NHLBI 2010 genome-wide & $7171[3955-12,581]$ & $3911[1649-8526]$ & $91,266[84,871-95,753]$ & $1956[435-5925]$ \\
\hline
\end{tabular}

Recommendation 1 is shown in the upper row. The lower row shows an extrapolation from the sample to the whole genome. Cells include the number of results to be communicated in each category, the associated percentage of disease-associated variants, and $95 \%$ confidence intervals. 
Estimated Growth of Known Variants and Growth of Obligated Communication

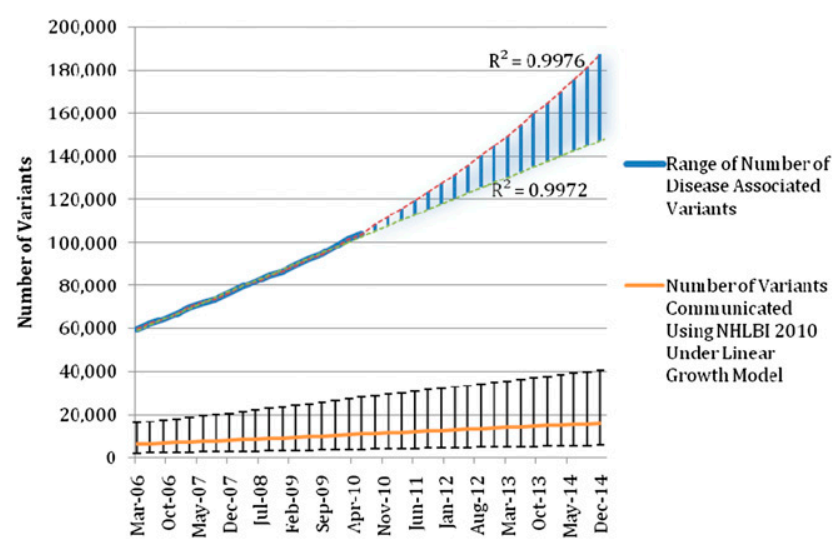

Figure 1. Estimated growth of the knowledge base of disease-associated variants and the number of variants that may meet the threshold for recommended communication to research participants. The quarterly totals of variants from the Human Gene Mutation Database and the National Human Genome Research Institute (NHGRI) Catalog of Published Genome-Wide Association Studies (GWAS) over $4 \mathrm{yr}$ were the basis for creating logarithmic (lower line) and exponential (upper line) regressions $\left(R^{2}=0.9976,0.9972\right)$. The range of likely growth is highlighted in blue between these two lines. These regressions were extrapolated to estimate the possible growth rates of disease-associated genetic variants in the following $4 \mathrm{yr}$. Linear growth rate data $\left(\mathrm{R}^{2}=0.9977\right)$ were also used to extrapolate the estimated number of variants that would be shared with research participants under the 2010 guidelines for disclosure. Bars, 95\% confidence intervals for each quarterly estimate.

This is a drastically larger burden on investigators than the review of a single neuroimaging study per participant-the impact on genomics research could be quite serious. Are we setting the stage for participants to be disappointed and for researchers to become legally liable for something they cannot realistically accomplish?

While published policy recommendations are certainly well intentioned, they are difficult to apply when such a large number of potential variants are worthy of communication to participants. We need more realistic standards that balance the ethical arguments in favor of disclosing results with the reality of what is feasible to review and communicate. Investigators and leaders of biorepositories will not be able to meet this potential ethical responsibility without substantial, evolving knowledge bases and enhanced processes. Additional questions from the current guidelines remain: Is CLIA certification really equivalent to analytic validity? What is the appropriate predictive risk cutoff for having clinical significance or "important health implications"? Does a GWAS-identified allele that increases relative risk for a rare disease by $10 \%$ warrant communication to participants?

Our estimates are based on an ambitious approach of investigating previously identified disease-associated variants that have been described in the scientific literature. To execute return of results at this level, researchers and research subjects would necessarily rely on yet-to-be developed tools for identifying and presenting variants of importance across the genome. In the meantime, as these genomescale decision and risk tools are developed, there are simple approaches to reduce the burden inherent in analyzing incidental findings in the clinical interpretation of whole-genome sequences. One is to limit reportable findings to those actually discovered during the normal course of research, likely including only a small set of genes. Alternatively, when the scope of the primary research is genome-wide, it may be more appropriate to ask investigators to check for a panel of well-known variants that meet a high standard of clinical significance and actionability, throughout the genome. Unfortunately, no such list yet exists.

The National Institutes of Health (NIH) is calling for empirically informed guidelines for the return of results (http://grants1.nih. gov/grants/guide/rfa-files/RFA-HG-10-017.html; http:/grants1.nih. gov/grants/guide/rfa-files/RFA-HG-11-003.html; http:/grants1. nih.gov/grants/guide/rfa-files/RFA-HG-11-004.html), in parallel, there should be support for new communication strategies and dynamic data sources to support this disclosure. While there are data sources emerging that measure the clinical and syntactic validity of previously identified variants (Khoury et al. 2009; http://evidence. personalgenomes.org/guide_impact_score; Tong et al. 2011), there is presently no knowledge base that includes the necessary information to reach disclosure decisions. One way to prospectively build such a database would be to create an obligation for investigators to report the novel variant associations identified in research studies. However, many investigators are not necessarily qualified to create clinical annotations that assess risk/benefit tradeoffs and other reportability criteria.

Further, how will the participant's clinical context (Beskow and Burke 2010) and preferences be taken into account? As the science and practice of full-genome interpretation matures (Ashley et al. 2010; Ormond et al. 2010), the next challenge becomes personalization of the communication strategy for very large numbers of variants, considering risks and benefits for each individual (Fabsitz et al. 2010; Kohane and Taylor 2010) that include the clinical validity and utility of each variant (Holtzman et al. 1997). While the disclosure of a small number of individual genetic risk variables has been measured in empirical trials (Green et al. 2009; Teutsch et al. 2009), these approaches are limited because of the sheer volume of variants that are and will become available, along with the changing nature of both the variant information and the therapeutic considerations that impact clinical utility. Although there is mounting evidence that participants are eager to receive a

Table 4. Estimated growth of disease-associated variants and the estimated growth of disease-associated variants that would meet the threshold for recommended disclosure over the next $4 \mathrm{yr}$

\begin{tabular}{lcc}
\hline Date & $\begin{array}{c}\text { Expected total } \\
\text { known variants }\end{array}$ & $\begin{array}{c}\text { Expected NHLBI 2010 potentially } \\
\text { communicated variants } \\
{[95 \% \text { confidence intervals] }}\end{array}$ \\
\hline Mar-06 & 59,666 & $6,339[3,989,9,835]$ \\
Mar-07 & 69,851 & $7,421[4,670,11,514]$ \\
Mar-08 & 79,651 & $8,462[5,326,13,129]$ \\
Mar-09 & 89,352 & $9,493[5,974,14,728]$ \\
Mar-10 & 101,686 & $10,804[6,799,16,761]$ \\
Mar-11 & 110,708 & $11,762[7,403,18,248]$ \\
Mar-12 & 121,091 & $12,865[8,097,19,960]$ \\
Mar-13 & 131,447 & $13,966[8,789,21,667]$ \\
Mar-14 & 141,803 & $15,066[9,482,23,374]$ \\
Mar-15 & 152,159 & $16,166[10,174,25,081]$ \\
\hline
\end{tabular}

We used data from two major sources of disease-associated variants (the Human Gene Mutation Database and the National Human Genome Research Institute Genome-Wide Association Studies Catalog) over the previous $4 \mathrm{yr}$ to estimate the growth of disease-associated variants and the number of those variants that would meet the threshold for disclosure to research participants. These estimates are based on the observed $10.6 \%$ variant disclosure rate from our sample when following National Heart, Lung, and Blood Institute (NHLBI) recommendation 1. In brackets are the 95\% confidence intervals for NHLBI disclosure estimates.

\section{Genome Research}


Table 5. Aggregate results from the whole-genome interpretation of 36 Complete Genomics genomes of asymptomatic individuals

\begin{tabular}{lccc}
\hline & $\begin{array}{c}\text { Total study } \\
\text { variants } \\
\text { identified }\end{array}$ & $\begin{array}{c}\text { Homozygous } \\
\text { study } \\
\text { variants }\end{array}$ & $\begin{array}{c}\text { Heterozygous } \\
\text { study } \\
\text { variants }\end{array}$ \\
\hline Minimum & 1812 & 623 & 1028 \\
Maximum & 2252 & 835 & 1371 \\
Average & 2120 & 737 & 1214 \\
Standard deviation & 70 & 54 & 74 \\
\hline
\end{tabular}

Whole-genome sequence data from 36 publicly available genomes of asymptomatic individuals (Drmanac et al. 2010; http://www. completegenomics.com/sequence-data/download-data/) were analyzed, using the substitution variants from the knowledge base in this study. The total number of variants identified in each sequence is reported, along with the subset of those that are homozygous and heterozygous.

broad range of genetic risk information upon contribution of materials and data to biorepository researchers (Murphy et al. 2008, 2009), many institutions have not recorded participant disclosure preferences. We have not explored such preferences in this study but, rather, started with the assumption that participants have consented to receive all possible results.

When there are results that participants have requested that meet the ethical criteria for disclosure, there is not yet a consensus on the proper mechanism for participant notification. There will be challenges in coordinating and funding this careful communication with research subjects, as many pure-science investigators do not have ready access to genetic counseling staff or other clinicians, and there is no broadly established mechanism for funding support for these endeavors.

There are several limitations to this study. The variant sample size is small in comparison to the number of known variants. While this creates broad confidence intervals, we are able to produce estimates that inform feasibility of the overall task. Also, in order to create a genome-wide estimate, our sampling strategy was inclusive of all possible variants in the knowledge bases we considered, rather than sampling the most frequently occurring variants. While these variants have been previously associated with disease in the scientific literature, they largely have been derived from small disease cohorts with limited control populations such that a reassessment of the evidence for pathogenicity is required. This process involves manual review of the evidence for each variant; however, we anticipate that a reasonable subset of variants will be filtered out as likely benign based upon the expanded frequency data that are emerging from whole-genome studies.

Additionally, for asymptomatic individuals, there is currently no authoritative source for relative risk of disease for the majority of variants in the knowledge bases we used; most manuscripts review a disease in the context of a small number of individuals, so there may be limitations to external generalizability that will be uncovered as new whole-genome data become available. When such data are reliably available, future studies should evaluate these estimates in the context of the likelihood of encountering each variant in participants. Additionally, there is no established quantitative standard in these published guidelines about what constitutes an "established and substantial" associated risk for disease. For this study, we relied on a human review process that was necessarily subjective, although we used a consensus-based process that reviewed a primary associated publication and clinical research data sources to increase objectivity. These reviews were conducted for research purposes, outside of the clinical context of specific patients, which presents limitations for robustness and external generalizability. The growth estimates are also based on the assumption that the pace of discovery will continue at current rates for the coming four years, however this rate of discovery may change over time.

Our findings have implications not only for genome researchers but also for clinicians. Microarrays and targeted sequencing are already used diagnostically, and it is anticipated that whole-genome sequencing will eventually be integrated into clinical care (Green and Guyer 2011). While suspicious lesions discovered during imaging research are routinely investigated clinically, our findings suggest that the same standard will not be feasible in genomic medicine. Issues to address in future research include diagnostic and intervention costs (both at present and downstream) and the decision support systems for prioritizing and communicating large numbers of variants, in conjunction with family history and/or clinical presentation.

\section{Methods}

\section{Sources of disease-associated variant data and creation of a study sample}

The set of variants for clinical annotation and review were randomly sampled, using a stratified methodology, from high-quality, curated databases (Table 6) that include a variety of variant types, including rare mutations, large insertions and deletions, rearrangements, and polymorphisms. These include the HGMD (Stenson et al. 2009), the NHGRI Catalog of Published GWAS (Hindorff et al. 2001) and the OMIM (Amberger et al. 2009). When variants were listed in more than one repository, duplicate entries were removed.

All variant records in the HGMD and NHGRI databases include an associated reference publication or locus-specific database (LSDB) entry that reports an association with a phenotype. All OMIM records have a corresponding OMIM entry, and many also have a reference publication.

We adopted a stratified sampling strategy to select a representative subset of variants that was drawn proportionally from each data source (Table 6). Each data source and variant category were evaluated separately (within HGMD, there are 10 variant types we consider in Table 6), and we substratified the sample among the subcategories in proportion to their frequencies. We first calculated the proportion of each variant type with respect to the entire set of variants we considered (104,304 total variants). We then multiplied that subset percentage by 160 and took the integer portion of that decimal number plus a simulated coin flip multiplied by the remaining (nondecimal) portion of the number to determine whether an extra variant would be sampled for that category. This resulted in an integer number of variants to review for each category. Though the large majority of variants are derived from HGMD, we proportionally sampled from all three databases.

To calculate the order of review for variants within each category, we assigned a randomly generated, unique number to each variant. The sampling strategy then rank-ordered each variant by its random number and included the determined number of variants from that category into the final variant sample.

\section{Exclusion criteria}

To avoid a bias toward selecting higher-quality studies, we evaluated and independently annotated as many of the sampled variants as possible. Two of 160 sampled variants were not analyzed 
Table 6. Variant types and data sources

\begin{tabular}{lccc}
\hline $\begin{array}{l}\text { Data source (date of access: type } \\
\text { of variants included) }\end{array}$ & $\begin{array}{c}\text { No. of } \\
\text { published } \\
\text { variants }\end{array}$ & $\begin{array}{c}\text { No. of } \\
\text { sampled } \\
\text { variants }\end{array}$ & $\begin{array}{c}\text { Percentage of } \\
\text { variants } \\
\text { in sample }\end{array}$ \\
\hline HGMD (March 2010: Mutations, Insertions, & 100,329 & 154 & 96.25 \\
$\quad$ Deletions, Other) & 56,457 & 86 & 53.75 \\
HGMD missense and nonsense & 15,805 & 24 & 15.00 \\
HGMD small deletions & 9,600 & 15 & 9.38 \\
HGMD splicing & 6,513 & 10 & 6.25 \\
HGMD small insertions & 6,201 & 10 & 6.25 \\
HGMD gross deletions & 1,766 & 3 & 1.88 \\
HGMD regulatory & 1,473 & 2 & 1.25 \\
HGMD small indels & 1,260 & 2 & 0.63 \\
HGMD gross insertions & 947 & 1 & 0.63 \\
HGMD complex rearrangements & 307 & 1 & 1.88 \\
HGMD repeat variations & 2,131 & 3 & 1.88 \\
NHGRI not in HGMD (January 2010: & 1,844 & 3 & 100 \\
Genome Wide Association Study SNPs) & & & \\
OMIM not in HGMD (June 2010: & 104,304 & 160 & \\
Single Nucleotide Substitutions) & & & \\
Total & & & \\
\hline
\end{tabular}

Variants were sampled from three different databases that curate genotype-phenotype associations derived from the scientific and medical literature. A stratified sampling method was used. HGMD indicates the Human Gene Mutation Database; NHGRI, National Human Genome Research Institute; and OMIM, Online Mendelian Inheritance in Man.

because the primary reference articles were not available in English, and another was excluded because there was no reference available. Excluded variants, where we were unable to create clinical annotations, were categorized as "unknown."

\section{Creating scores for each of the NHLBI 2010 recommendation criteria}

For each variant in the study sample, we created scores for the key factors cited in the NHLBI 2010 recommendations. We combined the areas of clinical review from NHLBI 2010 into three major axes: clinical impact of phenotype, clinical actionability, and association validity (Table 7).

Clinical impact of phenotype focuses on phenotype-specific characteristics, including reproductive impact and age of onset. Clinical actionability focuses on available medical interventions and preventative behaviors that may be applied, given knowledge of the phenotypic risk, including the efficacy of available interventions, and the impact on a patient's life when undergoing those interventions. The association validity focuses on the strength and validity of the reported genotype-phenotype associations, including a relative risk value (when available) and a scaled validity score.

Within each category or subcategory, we allowed for a range of scores, most often using a five-point rating scale (Supplemental Materials S1). Finally, we created written guidance to consistently categorize the scores for each clinical annotation component. We categorized the validity of the association as low, moderate, or high and supplemented that with an explanatory comment field that addressed the type of mutation, existence of consistent functional studies, and familial segregation, among other factors.

To generate consensus scores for each category, three certified genetic counselors reviewed supporting data from both clinical and research resources (including GeneReviews [Pagon 2006], OMIM [Amberger et al. 2009], and eMedicine [Q MRS 2002], among others) to contextualize the phenotype, determine the strength of the association between the variant and the disease, and identify any potential treatments. Additionally, we thoroughly reviewed the primary citation associated with each variant in the knowledge bases. Notably, each validity score is based only on the above data, an approach motivated by the significant time and resources that would be required to conduct an exhaustive literature review for a sample set of this size. Therefore, the validity scores are based on careful consideration of the presented data but are not derived from any specific algorithm and are categorized broadly as low, moderate, or high validity.

The genetic counselors clinically annotated each variant association, and when all three counselors were in agreement, the score was considered a final consensus score. Upon review of the available information, the genetic counselors were able to reach consensus in almost all but one case. However, where there was not a true consensus, the score was determined by the majority opinion, with two of the three counselors in agreement. Occasionally, a specific characteristic in a variant annotation was not scorable; some examples include a highly variable disease severity or age of onset, which we would mark as "variable" with a comment, or if insufficient information was available to reach a score, the characteristic was scored as "unknown." We marked items as "not applicable" when the score was not applicable to a specific variant or phenotype.

\section{Evaluating the responsibility for communication to a participant}

Once the representative sample of variants was clinically annotated, we evaluated whether each variant would be appropriate for communication to research participants using communication strategies derived from the NHLBI 2010 Working Group.

We matched each characteristic from the disclosure guidelines to a characteristic from the clinical annotations created by the genetic counselors, including strength of association, phenotypic severity, and improvement with treatment. If the score for each characteristic met the definition for the associated disclosure criterion, the variant qualified for the recommendation to disclose to participants. This is illustrated as the gray portion of Table 2 . If one or more criteria were missing or unknown, the responsibility to disclose was designated as " unknown." If all disclosure criteria were met but the phenotypic severity was considered variable and had

Table 7. Clinical annotation characteristics

\begin{tabular}{lc}
\hline Categories & \multicolumn{1}{c}{ Characteristics } \\
\hline $\begin{array}{c}\text { Clinical impact } \\
\text { of phenotype }\end{array}$ & $\begin{array}{c}\text { Severity with treatment, severity without } \\
\text { treatment, age of onset, } \\
\text { and reproductive issues } \\
\text { Efficacy of available treatment, invasiveness } \\
\text { and difficulty of treatment, frequency } \\
\text { and duration of treatment } \\
\text { Clinical } \\
\text { actionability }\end{array}$ \\
Association validity and relative \\
risk (when applicable)
\end{tabular}

A team of three certified genetic counselors used a consensus-based method to create clinical annotations for each variant in three categories: clinical impact of phenotype, clinical actionability, and association validity. For each of these categories, a set of characteristics was scored for each variant, most often using a rating scale.

\section{Genome Research}


the potential to meet the threshold to disclose, then that variant was labeled "variable."

To focus this study on identifying the number of variants recommended for disclosure to research participants, we excluded a number of external factors from consideration. We specified that all participants would have consented to learning about variants they carried, that the genetic assay would have met analytic validity standards, and that the disclosure of results to participants was Institutional Review Board (IRB)-approved and met all state and federal laws.

\section{Estimating the number of variants genome-wide that met the threshold for recommendation to communicate under NHLBI 2010}

To estimate the number of variants, genome-wide, that would meet the threshold for recommended disclosure, we used the observed proportion of sampled variants that fulfilled the requirements for recommended reporting (6.88\%, plus an additional 3.75\% under the less strict interpretation). To reach the estimate, we used the sampling fraction, the proportion of the variants that we sampled from the total variant knowledge base that was considered in this study. We divided the number of variants that met the threshold for recommended or potential communication under each disclosure strategy by the sampling fraction to reach an estimate of variants from the total variant knowledge base that would meet each set of criteria.

In addition to the estimate that was generated, we used the Agresti-Coull binomial confidence interval method (Brown et al. 2001) to calculate $95 \%$ confidence intervals for each disclosure result. Because the sample was drawn from a finite population of variants, we completed a finite population correction factor, and the effect was negligible because the sample size was small in comparison to the total number of variants.

\section{Potential growth of number of variants that would be disclosed to participants under NHLBI 2010}

We estimated the potential growth of disease-associated variants using data from the HGMD and the NHGRI Catalog of Published GWAS (which represented over 98\% of the variants in our knowledge base). We applied standard regression analysis to quarterly reports of total variant counts from the previous $4 \mathrm{yr}$, calculating logarithmic, linear, and exponential regression models, and estimated the future growth of variants following a linear trend over the following four years.

\section{Number of previously identified substitution variants detected in the whole-genome analysis of $\mathbf{3 6}$ asymptomatic individuals}

We compared the whole-genome sequence data from 36 asymptomatic individuals that are publicly available from Complete Genomics with all substitution variants from the knowledge base used in this study (Drmanac et al. 2010; http://www.completegenomics.com/ sequence-data/download-data/). We then calculated the maximum, minimum, and average number of variants that were identified in each sample, and also recorded whether each variant was heterozygous or homozygous in each individual.

\section{Acknowledgments}

This research was supported by grant LM010470-01 from the National Library of Medicine and the Manton Center for Orphan Diseases at Children's Hospital Boston (K.D.M.), by training grant HD040128 from the National Institute of Child Health and Human Development (C.A.C.), by HG02213, HG005092, and AG027841
(R.C.G.), and by the BCM Clinical and Translational Research Program and the Baylor Annual Fund (A.L.M). We thank our genetic counselors, Meghan Connolly and Catherine Clinton, for their service on the expert committee. We also thank Dr. Mark Tong for his assistance in the whole-genome analysis of the Complete Genomics samples.

\section{References}

Amberger J, Bocchini CA, Scott AF, Hamosh A. 2009. McKusick's Online Mendelian Inheritance in Man (OMIM). Nucleic Acids Res 37: D793D796.

Ashley EA, Butte AJ, Wheeler MT, Chen R, Klein TE, Dewey FE, Dudley JT, Ormond KE, Pavlovic A, Morgan AA, et al. 2010. Clinical assessment incorporating a personal genome. Lancet 375: 1525-1535.

Beskow LM, Burke W. 2010. Offering individual genetic research results: context matters. Sci Transl Med 2: 38cm20. doi: 10.1126/ scitranslmed.3000952.

Beskow LM, Burke W, Merz JF, Barr PA, Terry S, Penchaszadeh VB, Gostin LO, Gwinn M, Khoury MJ. 2001. Informed consent for population-based research involving genetics. JAMA 286: 2315-2321.

Blow N. 2009. Biobanking: freezer burn. Nat Methods 6: 173-178.

Bookman EB, Langehorne AA, Eckfeldt JH, Glass KC, Jarvik GP, Klag M, Koski G, Motulsky A, Wilfond B, Manolio TA, et al. 2006. Reporting genetic results in research studies: summary and recommendations of an NHLBI working group. Am J Med Genet A 140: 1033-1040.

Brown L, Cai T, DasGupta A. 2001. Interval estimation for a binomial proportion. Stat Sci 16: 101-133.

Caulfield T, McGuire AL, Cho M, Buchanan JA, Burgess MM, Danilczyk U, Diaz CM, Fryer-Edwards K, Green SK, Hodosh MA, et al. 2008. Research ethics recommendations for whole-genome research: consensus statement. PLOS Biol 6: e73. doi: 10.1371/journal.pbio.0060073.

Drmanac R, Sparks AB, Callow MJ, Halpern AL, Burns NL, Kermani BG, Carnevali P, Nazarenko I, Nilsen GB, Yeung G, et al. 2010. Human genome sequencing using unchained base reads on self-assembling DNA nanoarrays. Science 327: 78-81.

Fabsitz RR, McGuire AL, Fabsitz RR, McGuire A, Sharp RR, Puggal M, Beskow LM, Biesecker LG, Bookman E, Burke W, et al. 2010. Ethical and practical guidelines for reporting genetic research results to study participants: updated guidelines from a National Heart, Lung, and Blood Institute Working Group. Circ Cardiovasc Genet 3: 574-580.

Fernandez CV, Weijer C. 2006. Obligations in offering to disclose genetic research results. Am J Bioeth 6: 44-46.

Fernandez CV, Kodish E, Weijer C. 2003. Informing study participants of research results: an ethical imperative. IRB 25: 12-19.

Fitzpatrick RB. 2002. eMedicine. Med Ref Serv Q 21: 47-54.

Green ED, Guyer MS. 2011. Charting a course for genomic medicine from base pairs to bedside. Nature 470: 204-213.

Green RC, Roberts JS, Cupples LA, Relkin NR, Whitehouse PJ, Brown T, Eckert SL, Butson M, Sadovnick AD, Quaid KA, et al. 2009. Disclosure of APOE genotype for risk of Alzheimer's disease. N Engl J Med 361: $245-254$

Hindorff LA, MacArthur J (European Bioinformatics Institute), Wise A, Junkins HA, Hall PN, Klemm AK, and Manolio TA. 2011. A Catalog of Published Genome-Wide Association Studies. www.genome.gov/gwastudies.

Holtzman NA, Murphy PD, Watson MS, Barr PA. 1997. Predictive genetic testing: from basic research to clinical practice. Science 278: 602-605.

Illes J, Rosen AC, Huang L, Goldstein RA, Raffin TA, Swan G, Atlas SW. 2004 Ethical consideration of incidental findings on adult brain MRI in research. Neurology 62: 888-890.

Illes J, Tairyan K, Federico CA, Tabet A, Glover GH. 2010. Reducing barriers to ethics in neuroscience. Front Hum Neurosci 4: pii. doi: 10.3389/ fnhum.2010.00167.

Johnson AD, Bhimavarapu A, Benjamin EJ, Fox C, Levy D, Jarvik GP O'Donnell CJ. 2010. CLIA-tested genetic variants on commercial SNP arrays: potential for incidental findings in genome-wide association studies. Genet Med 12: 355-363.

Khoury MJ, Feero WG, Reyes M, Citrin T, Freedman A, Leonard D, Burke W, Coates R, Croyle RT, Edwards K, et al. 2009. The genomic applications in practice and prevention network. Genet Med 11: 488-494.

Kohane IS, Taylor PL. 2010. Multidimensional results reporting to participants in genomic studies: getting it right. Sci Transl Med 2: $37 \mathrm{~cm} 19$. doi: 10.1126/scitranslmed.3000809.

Kohane IS, Masys DR, Altman RB. 2006. The incidentalome: a threat to genomic medicine. JAMA 296: 212-215.

Kohane IS, Mandl KD, Taylor PL, Holm IA, Nigrin DJ, Kunkel LM. 2007. Medicine. Reestablishing the researcher-patient compact. Science 316: 836-837. 


\section{Cassa et al.}

Kozanczyn C, Collins K, Fernandez CV. 2007. Offering results to research subjects: U.S. Institutional Review Board policy. Account Res 14: 255267.

MacNeil SD, Fernandez CV. 2006. Offering results to research participants. BMJ 332: 188-189.

McGuire AL. 2008. 1000 genomes on the road to personalized medicine. Per Med 5: 195-197.

Meltzer LA. 2006. Undesirable implications of disclosing individual genetic results to research participants. Am J Bioeth 6: 28-30.

Murphy J, Scott J, Kaufman D, Geller G, LeRoy L, Hudson K. 2008. Public expectations for return of results from large-cohort genetic research. Am J Bioeth 8: 36-43.

Murphy J, Scott J, Kaufman D, Geller G, LeRoy L, Hudson K. 2009. Public perspectives on informed consent for biobanking. Am J Public Health 99: 2128-2134

Ormond KE, Wheeler MT, Hudgins L, Klein TE, Butte AJ, Altman RB, Ashley EA, Greely HT. 2010. Challenges in the clinical application of wholegenome sequencing. Lancet 375: 1749-1751.

Pagon RA. 2006. GeneTests: an online genetic information resource for health care providers. J Med Libr Assoc 94: 343-348.

Palmour N, Affleck W, Bell E, Deslauriers C, Pike B, Doyon J, Racine E. 2011. Informed consent for MRI and fMRI research: analysis of a sample of Canadian consent documents. BMC Med Ethics 12: 1. doi: 10.1186/ 1472-6939-12-1.

Roden DM, Pulley JM, Basford MA, Bernard GR, Clayton EW, Balser JR, Masys DR. 2008. Development of a large-scale de-identified DNA biobank to enable personalized medicine. Clin Pharmacol Ther 84: 362-369.
Sadatsafavi M, Marra C, Li D, Illes J. 2010. An ounce of prevention is worth a pound of cure: a cost-effectiveness analysis of incidentally detected aneurysms in functional MRI research. Value Health 13: 761-769.

Stenson PD, Ball EV, Howells K, Phillips AD, Mort M, Cooper DN. 2009. The Human Gene Mutation Database: providing a comprehensive central mutation database for molecular diagnostics and personalized genomics. Hum Genomics 4: 69-72.

Teutsch SM, Bradley LA, Palomaki GE, Haddow JE, Piper M, Calonge N, Dotson WD, Douglas MP, Berg AO. 2009. The Evaluation of Genomic Applications in Practice and Prevention (EGAPP) Initiative: methods of the EGAPP Working Group. Genet Med 11: 3-14.

Tong MY, Cassa CA, Kohane IS. 2011. Automated validation of genetic variants from large databases: Ensuring that variant references refer to the same genomic locations. Bioinformatics 27: 891-893.

White MT, Gamm J. 2002. Informed consent for research on stored blood and tissue samples: a survey of institutional review board practices. Account Res 9: 1-16.

Wolf SM, Lawrenz FP, Nelson CA, Kahn JP, Cho MK, Clayton EW, Fletcher JG, Georgieff MK, Hammerschmidt D, Hudson K et al. 2008a. Managing incidental findings in human subjects research: analysis and recommendations. J Law Med Ethics 36: 219-248.

Wolf SM, Paradise J, Caga-anan C. 2008b. The law of incidental findings in human subjects research: establishing researchers' duties. J Law Med Ethics 36: 361-383.

Received June 16, 2011; accepted in revised form November 23, 2011. 


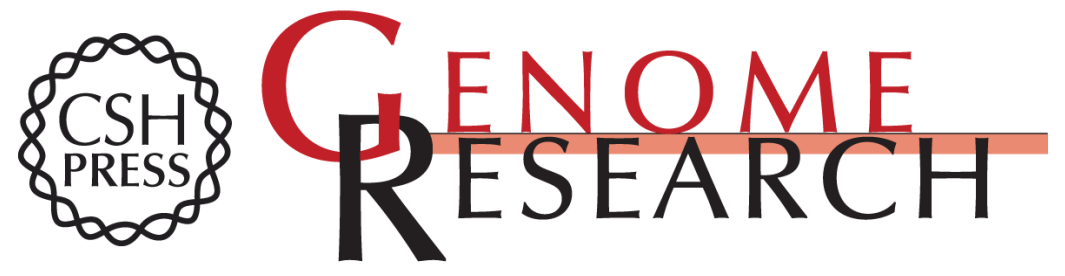

\section{Disclosing pathogenic genetic variants to research participants: Quantifying an emerging ethical responsibility}

Christopher A. Cassa, Sarah K. Savage, Patrick L. Taylor, et al.

Genome Res. 2012 22: 421-428 originally published online December 6, 2011

Access the most recent version at doi:10.1101/gr.127845.111

Supplemental Material

References This article cites 40 articles, 8 of which can be accessed free at: http://genome.cshlp.org/content/22/3/421.full.html\#ref-list-1

Open Access Freely available online through the Genome Research Open Access option.

License Freely available online through the Genome Research Open Access option.

Email Alerting
Service
top right corner of the article or click here.

\section{Affordable, Accurate Sequencing.}

